\title{
Quench induced residual stress prediction in heat treatable 7xxx aluminium alloy thick plates using Gleeble interrupted quench tests
}

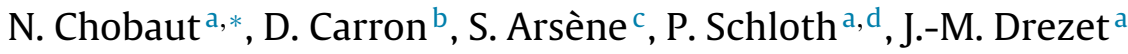 \\ a Ecole Polytechnique Fédérale de Lausanne, LSMX, Station 12, CH-1015 Lausanne, Switzerland \\ ${ }^{\mathrm{b}}$ Univ Bretagne-Sud, EA 4250, LIMATB, F-56100 Lorient, France \\ ' Constellium Technology Center, 725 rue Aristide Bergès, Centr'Alp, 38341 Voreppe, France \\ d Ecole Polytechnique Fédérale de Lausanne, NXMM, Station 12, CH-1015 Lausanne, Switzerland
}

\section{A R T I C L E I N F O}

Article history:

Received 23 November 2014

Received in revised form 17 March 2015

Accepted 21 March 2015

Available online 28 March 2015

\section{Keywords:}

AA7xxx alloys

Residual stress

Precipitation

Gleeble machine

Neutron diffraction

\begin{abstract}
A B S T R A C T
In this paper, a simple but realistic approach is presented to predict the as-quenched residual stress distribution in thick $7 \mathrm{xxx}$ aluminium alloy plates. Instead of modelling precipitation that occurs during quenching, a thermo-mechanical model is used whose parameters are identified using a limited number of tensile tests achieved after representative interrupted cooling paths in a Gleeble machine. The material behaviour law accounts for recovery at high temperature in a simple way and neglects the Bauschinger effect as suggested by a dedicated experiment. The results of this simple approach are compared to residual stress measurements in plates of different thicknesses for two different 7xxx alloys, AA7449 and AA7040.
\end{abstract}

(c) 2015 Elsevier B.V. All rights reserved.

\section{Introduction}

In the fabrication of heat treatable aluminium parts for the aerospace industry, solution heat treatment (SHT) and quenching are key steps in order to obtain the required mechanical characteristics. The objective of SHT is to obtain a solid solution at equilibrium. The objective of quenching is to cool the material to room temperature as quickly as possible, obtaining a state called non-equilibrium solid solution (neSS) as close as possible to solid solution at the end of the quench. Quenching should thus be fast in order to avoid or limit precipitation. However, high thermal gradients through the thickness cause non-homogeneous plastic strain resulting in residual stresses (RS) after quenching. Robinson et al. (2014) showed that surface RS measured by X-ray diffraction on AA7010 cold-water-quenched rectangular blocks increase when the thickness increases from $16 \mathrm{~mm}$ to $124 \mathrm{~mm}$. Quenching is thus followed by a stress relief, as explained by Jeanmart and Bouvaist (1985), that reduces residual stresses by a factor of approximately 10 as shown by Boyer and Boivin (1985). An ageing treatment is performed to transform elements in solid solution into fine hardening precipitates and thus increase the yield strength. In thick 7xxx

\footnotetext{
* Corresponding author. Tel.: +4121693 3920.

E-mail address: jean-marie.drezet@epfl.ch (N. Chobaut).
}

highly alloyed wrought products, even reduced by stress relief, these RS at final temper can lead to distortions during machining of large and complex parts, see for example Dubost et al. (1989). For the prediction of these RS, it is thus important to be able to model the full process and particularly the quenching. It is the first step since a stress relief model has to use RS after quenching as its initial state.

Precipitation phenomena may affect RS. For instance, it is well known for such thick plates that the cooling during quenching is not fast enough at mid-thickness to prevent any precipitation. This decreases the efficiency of ageing as shown by Robinson et al. (2014) but also may affect the as-quenched yield strength and consequently the RS distribution according to the calculations of Godard et al. (1999). In 7xxx alloys, two types of precipitation may occur during quenching depending on the cooling rate, see Dumont et al. (2004). For low cooling rates, a first precipitation occurs at intermediate temperature, typically $400-250^{\circ} \mathrm{C}$ as shown by Chobaut et al. (2014) for AA7010 and by Schloth et al. (2014) for AA7449. The large precipitates formed are undesirable since they reduce the amount of elements in solid solution and do not harden the material significantly. A second precipitation occurs at low temperature, typically below $220^{\circ} \mathrm{C}$ as evidenced by Godard et al. (2002) for AA7010 and below $300-250^{\circ} \mathrm{C}$ for AA7449 according to Schloth et al. (2014). In the case of a $200 \mathrm{~mm}$ thick AA7010 water-quenched plate, Godard et al. (1999) have shown that the 
resulting effect of these two types of precipitation is an increase of the yield strength at plate surface after quenching compared to that of the neSS.

Quenching of thick aluminium plates leads to plastic deformation resulting in surface compressive stresses balanced by core tensile stresses after quench, see Boyer and Boivin (1985). In the particular case of cold water quenching of thick plates, the surface deforms plastically at high temperature but also at low temperature as shown by Godard et al. (1999). The magnitude of the surface compressive stress depends thus on the yield strength but also on the plastic deformation accumulated during quenching at the plate surface. The plate mid-thickness area may also deform plastically down to room temperature but less than the surface. Between quarter-thickness and mid-thickness, the material remains purely elastic at low temperature.

For thin plates, a thermo-mechanical model ignoring precipitation is sufficient to predict as-quenched RS satisfactorily. This is because the quenching is fast so the precipitation is inhibited and the plasticity does not occur at low temperature, see Jeanmart and Bouvaist (1985). In the case of 7xxx highly alloyed thick plates, a thermo-mechanical model that does not account for the increase of yield strength by precipitation hardening underestimates RS as shown by Chobaut et al. (2012). The general approach to take into account precipitation is to use yield strength and strain hardening models where the flow stress depends on the precipitation state calculated by a precipitation model, see for example Deschamps and Brechet (1998). Godard et al. (1999) neglected the effect of precipitation on strain hardening and used a physically based model for the yield strength. This model required an extensive mechanical characterisation of the influence of precipitation on flow stress as shown in the work of Godard et al. (1998).

The goal of the present work is to show that the precipitation can be taken into account in a very simplified way for modelling of cold-water-quench of plates with thicknesses lower than $150 \mathrm{~mm}$ of highly alloyed 7xxx alloys with a reasonable accuracy. This simple model requires only a few Gleeble interrupted tests for a given alloy and each plate thickness.

The results of this simple model accounting for precipitation, together with those obtained with a model ignoring precipitation, are then compared to residual stress measurements in plates of different thicknesses for two different 7xxx alloys, AA7449 and AA7040.

\section{Modelling}

\subsection{Thermo-mechanical model of quenching}

The vertical quenching in cold water of AA7449 and AA7040 thick plates was simulated using a thermo-mechanical model similar to the one used by Jeanmart and Bouvaist (1985) and implemented in the commercial finite element (FE) code ABAQUS 6.10. This pseudo-2D model, assuming that the plate is infinite, was chosen for its simplicity. It consists of one row of axisymmetric elements through the plate thickness. In this model, only the inplane components $\sigma_{x x}$ and $\sigma_{y y}$ of the stress tensor are non-zero as verified experimentally by Chobaut et al. (2012) using neutron diffraction and by Drezet et al. (2013) using Layer Removal. In this model, stress components are:

$\sigma_{x x}(z)=\sigma_{y y}(z), \sigma_{x y}=\sigma_{x z}=\sigma_{y z}=0, \sigma_{z z}(z)=0$ and $\left|\sigma_{x x}\right|=\bar{\sigma}$

where $x$ and $y$ are the in-plane directions, $z$ is the short transverse direction and $\bar{\sigma}$ is the von Mises equivalent stress. In order to predict the as-quenched RS, one needs to have an accurate knowledge of the temperature field evolution in the plate. A non-linear heat transfer analysis is performed using temperature-dependent thermal conductivity and specific heat. Surface heat flux is modelled with a Cauchy boundary condition using a temperaturedependent heat transfer coefficient determined by Yu and Robinson (2007) in the frame of the European project COMPACT(Section 3.2).

\subsection{Thermo-mechanical behaviour}

To compute internal strains and stresses in the processing steps of heat treatable aluminium alloys, it is generally assumed that the total strain is the sum of the elastic, thermal and plastic strains, thus neglecting the transformation strain including volume changes and transformation plasticity. During quenching where both high temperature and low temperature deformations are encountered, the classical plasticity theory, which relies on the accumulated equivalent plastic strain predicts stresses at low temperature higher than the measured ones, see Mo and Holm (1993). Indeed, Mo and Farup (2000) have shown that high temperature strain has no influence on later low temperature mechanical behaviour. This phenomenon is attributed to dislocation annihilation, which is thermally activated and dominates over dislocation storage at high temperature. The present model takes into account this phenomenon with a parameter called $T_{\text {cum. }}$. Above $T_{\text {cum }}$, the equivalent plastic strain has no influence on the flow strength. Below $T_{\text {cum }}$, the equivalent plastic strain has a full effect on the flow strength, since annihilation of dislocations is negligible in the under-aged state as reported by Fribourg et al. (2011). The accumulated equivalent plastic strain, $p_{\text {cum }}$, is thus defined as:

$$
\begin{aligned}
& p_{\text {cum }}=\left\{\begin{array}{l}
\int \dot{p} d t \text { when } T<T_{\text {cum }} \\
0 \text { when } T>T_{\text {cum }}
\end{array}\right. \\
& \text { with } p=\sqrt{\frac{2}{3} \dot{\mathcal{\varepsilon}}^{p}: \dot{\sim}^{p}} \text { in } 3 D \text { and } \dot{p}=\left|\dot{\varepsilon}^{p}\right| \text { in } 1 D
\end{aligned}
$$

where $T_{\text {cum }}$ is the temperature above which plastic deformation has no effect on low temperature later behaviour and the plastic strain rate, $\dot{\varepsilon}^{p}$, is a second-order tensor in $3 \mathrm{D}, \dot{\tilde{\varepsilon}}^{p}$.

In order to determine this temperature, tensile tests at low temperature are performed in this work after straining at high temperature as suggested by Alankar and Wells (2010). A similar approach was used by Haaften et al. (2002) but with a smooth transition from "recovery" above $400{ }^{\circ} \mathrm{C}$ to hardening-dominated behaviour below $250^{\circ} \mathrm{C}$ instead of the sharp transition associated with the use of $T_{\text {cum. }}$. This is an alternative to the use of a MATMOD (standing for MATerials MODel) set of constitutive equations, as described by Miller (1987). This approach, based on the concept of internals variables, treats plasticity and creep in a unified manner and can simulate recovery, see for example Järvstråt and Tjøtta (1996). It is also a substitute for using more complex strain hardening models describing the evolution of dislocation density with strain as a competition between storage and annihilation.

Besides known physical data (elastic modulus, Poisson's ratio and coefficient of thermal expansion), other mechanical parameters $\left(\sigma_{0}, H, n, K, m\right)$ are needed to describe the mechanical behaviour of both AA7xxx alloys, from the solutionising temperature to room temperature. Following Colonna et al. (1992), an additive constitutive equation (Chaboche-type model) is used to combine both isotropic strain hardening and viscoplastic phenomena:

$\bar{\sigma}=\sigma_{0}+H\left(p_{\text {cum }}\right)^{n}+K(\dot{p})^{m}$

where $\sigma_{0}$ represents a threshold stress, $H$ and $n$ are hardening parameters, $K$ is the consistency (viscous parameter) and $m$ is the strain rate sensitivity parameter.

The use of Eq. (3), which considers only isotropic hardening, is justified by low plastic strains (of the order of $1 \%$ in quenching) together with the low Bauschinger effect for under-aged states 
reported by Reich and Kessler (2011) for 6xxx alloys, by Fribourg et al. (2011) for AA7449 and checked in this work for AA7040 (Section 4.3).

Among the parameters of the plastic behaviour $\sigma_{0}, H, n, K$ and $m$, whose temperature evolution is to be determined, $\sigma_{0}$ is claimed to be the one mainly affected by precipitation according to Denis et al. (2002). It depends on the size and volume fraction of precipitates as well as on solute concentration in the matrix, see for example, Myhr et al. (2001). In turn, strain hardening is considered little affected by precipitation in the work of Godard (1999) as checked in this work (Section 4.1).

At high temperature $\left(\geq 250^{\circ} \mathrm{C}\right)$, a few Gleeble tests after rapid cooling were performed for each alloy to feed both models (simple model accounting for precipitation and model without precipitation).

In the simple model accounting for precipitation, the mechanical behaviour does not depend on any internal variable that could represent the precipitation and the material behaviour is homogeneous through the plate thickness (Eq. (3) is used for the whole thickness). This assumption holds at high temperature $\left(>200^{\circ} \mathrm{C}\right)$ if the effect of high temperature precipitation on flow stress is negligible. It is not the case at room temperature since the cooling path depends on the position through the thickness of the plate and so the local precipitation state is unique. Nevertheless, as for thick plates the plasticity occurs mainly near the surface, $\sigma_{0}$ in the model can be considered as temperature-dependent only, provided that it is experimentally determined through Gleeble interrupted quench tests just after a cooling similar to that of the surface during quenching (later called "surface cooling"). This is a simplified way to take into account precipitation. It requires two Gleeble tests at low temperature $\left(25^{\circ} \mathrm{C}\right.$ and $\left.100^{\circ} \mathrm{C}\right)$ where the plate surface yields. These two tests are performed for each plate thickness and each alloy since the cooling path depends on these two parameters.

For the model without precipitation, $\sigma_{0}$ at low temperature was determined from Gleeble tests after very rapid cooling. Tensile tests were performed in the Gleeble after water cooling interrupted at $100^{\circ} \mathrm{C}$ and $20^{\circ} \mathrm{C}$ (not shown here) to characterise the neSS and feed the FE model without precipitation.

\section{Experimental}

\subsection{Materials}

The composition of AA7449 and AA7040 is given in Table 1. AA7040 has a lower solute content since it has been designed for very thick plates requiring a low quench sensitivity.

$20 \mathrm{~mm}$ and $75 \mathrm{~mm}$ thick AA7449 hot-rolled plates, as well as $75 \mathrm{~mm}$ and $140 \mathrm{~mm}$ thick AA7040 hot-rolled plates were supplied by Constellium.

\subsection{Quenching and temperature measurements during quench}

For subsequent RS measurements, AA7449 and AA7040 plates were vertically quenched by immersion in an experimental medium size agitated $20^{\circ} \mathrm{C}$ water quench device. One of the $75 \mathrm{~mm}$ thick AA7449 plates was drilled perpendicular to the thermal gradient at 3,15 and $37.5 \mathrm{~mm}$ from the surface and equipped with three thermocouples inserted in the holes. Temperature measurements during quenching compare well with the results of a FE simulation using the global heat transfer coefficient (HTC) determined by Yu and Robinson (2007) on $75 \mathrm{~mm}$ thick AA7449 plates in the frame of the COMPACT project. This HTC was used to calculate the surface cooling cycle to be imposed within the Gleeble specimens. It is assumed to be identical for both the $20 \mathrm{~mm}$ and $75 \mathrm{~mm}$ thick AA7449 plates, as well as the $75 \mathrm{~mm}$ and $140 \mathrm{~mm}$ thick AA7040 plates. For as-quenched RS prediction, this HTC was also used to calculate the temperature field evolution in the plates.

\subsection{Gleeble tests}

Gleeble tensile test specimens were directly machined in the hot rolled plates. They were sampled in the rolling direction at quarter thickness of the $75 \mathrm{~mm}$ plates in AA7449 and in AA7040 in order to ensure a maximal homogeneity of composition and grain structure. In this work, before being tested, the specimens were pre-solutionised in a furnace for $4 \mathrm{~h}$ at $472{ }^{\circ} \mathrm{C}$ for AA7449 and $480^{\circ} \mathrm{C}$ for AA7040.

The Gleeble machine is an appropriate tool to achieve complex cooling paths in order to obtain a desired metallurgical state and characterise the corresponding mechanical behaviour. It was selected to carry out the thermo-mechanical tests because of its reliability in controlling temperature, jaw velocity and force. Specimens are held horizontally by water cooled grips, heated via Joule effect and cooled by copper grips and additional air cooling. A closed-loop feedback control system enables precise control of the heat input based on the temperature monitored by the central thermocouple TC1 fixed at the specimen surface. An optimised geometry was designed (Fig. 1) to localise strains at the mid-length of the specimen where the cross section is minimal while keeping the inherent axial thermal gradient as low as possible as shown by Norris and Wilson (1999). This thermal gradient is controlled by TC 2 and TC 3 thermocouples. Strain measurements are achieved with a diametral extensometer carefully positioned at the midlength of the specimen.

Hoop strains $\varepsilon_{\theta^{\prime} \theta^{\prime}}$ measured by the diametral extensometer are transformed to axial strains $\varepsilon_{z^{\prime} z^{\prime}}$ using:

$\varepsilon_{z^{\prime} z^{\prime}}=\frac{1-2 v}{E} \sigma_{z^{\prime} z^{\prime}}-2 \varepsilon_{\theta^{\prime} \theta^{\prime}}$

where the Poisson's ratio $v$ is taken constant (0.33) and the Young's modulus $E$ is temperature dependent. Eq. (4) is valid for a tensile test at constant temperature as performed experimentally. The combination of copper grips and the optimised geometry allow obtaining a maximum cooling rate of $150^{\circ} \mathrm{C} / \mathrm{s}$ with additional air cooling. The tensile tests are performed at constant displacement rates. Force is measured using a $100 \mathrm{kN}$ load cell.

\subsection{RS measurements}

Neutron diffraction was used to non-destructively measure through the plate thickness RS for the three thicknesses and two alloys investigated. Residual strain measurements in $75 \mathrm{~mm}$ thick as-quenched AA7040 and AA7449 plates were already described in the work of Drezet et al. (2013). Additionally, a $500 \mathrm{~mm} \times 300 \mathrm{~mm} \times 20 \mathrm{~mm}$ as-quenched AA7449 plate was measured at the POLDI diffractometer (PSI, Switzerland) and a $600 \mathrm{~mm} \times 400 \mathrm{~mm} \times 140 \mathrm{~mm}$ as-quenched AA7040 plate was measured at the SALSA diffractometer (ILL, France). The measurement method is fully detailed in the work of Chobaut et al. (2012).

The layer removal method was used to measure through the thickness RS in a $700 \mathrm{~mm} \times 405 \mathrm{~mm} \times 75 \mathrm{~mm}$ as-quenched AA7449 plate. Two full thickness rectangular bars were taken in the $\mathrm{x}$ and $y$ directions of the middle of a $75 \mathrm{~mm}$ thick AA7449 plate. The $30 \mathrm{~mm} \times 250 \mathrm{~mm} \times 75 \mathrm{~mm}$ bars were machined down the $z$ direction by steps of $2 \mathrm{~mm}$. RS in the plate are calculated from elastic strains measured by a strain gauge bound to the surface opposite to the machined surface. The measurement method is presented in the work of Jeanmart and Bouvaist (1985) and further detailed in the patent by Boselli et al. (2005). 
Table 1

Composition of AA7449 and AA7040 in weight percent, balance Al.

\begin{tabular}{|c|c|c|c|c|c|c|c|c|c|}
\hline & $\mathrm{Si}$ & $\mathrm{Fe}$ & $\mathrm{Cu}$ & Mn & $\mathrm{Mg}$ & $\mathrm{Cr}$ & $\mathrm{Zn}$ & $\mathrm{Ti}$ & Others \\
\hline AA7449 & 0.12 & 0.15 & $1.4-2.1$ & 0.20 & $1.8-2.7$ & - & $7.5-8.7$ & & $0.25 \mathrm{Ti}+\mathrm{Zr}$ \\
\hline AA7040 & 0.10 & 0.13 & $1.5-2.3$ & 0.04 & $1.7-2.4$ & 0.04 & $5.7-6.7$ & 0.06 & $0.05-0.12 \mathrm{Zr}$ \\
\hline
\end{tabular}

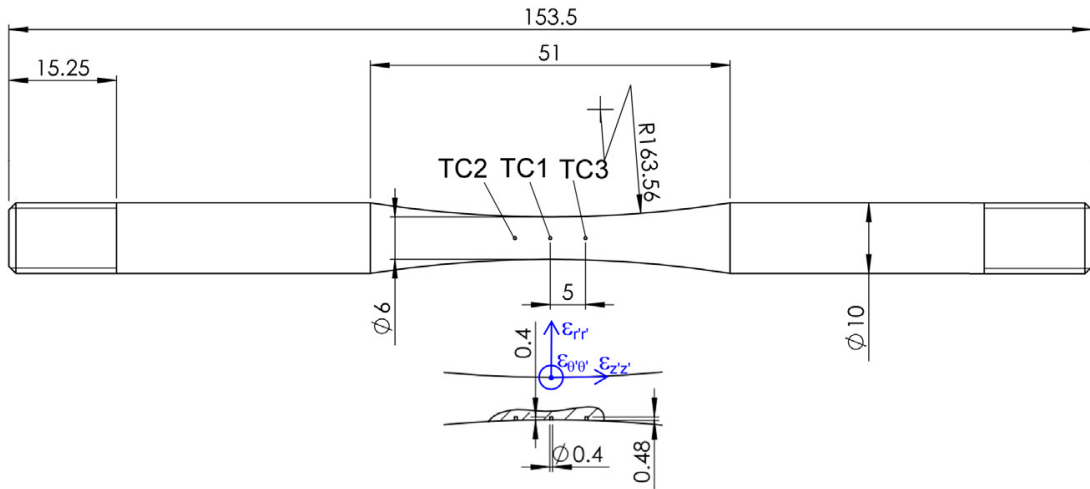

Fig. 1. Specimen geometry used for tensile test in the Gleeble machine (dimensions in millimetres).

\section{Results and discussion}

\subsection{Tensile tests after plate surface coolings}

Specimens were heated in the Gleeble from room temperature to the SHT temperature at $30^{\circ} \mathrm{C} / \mathrm{s}$ and solutionised for $3 \mathrm{~min}$ at the SHT temperature. For each alloy, one specimen was subjected at the SHT temperature to a succession of tensile loads at different strain rates interrupted by a pseudo-relaxation (blocked jaws) during $90 \mathrm{~s}$. The other specimens were cooled to follow accurately the surface coolings of plates with different thicknesses determined by the heat transfer simulation. The coolings were interrupted either at $325^{\circ} \mathrm{C}, 265^{\circ} \mathrm{C}, 250^{\circ} \mathrm{C}, 100^{\circ} \mathrm{C}, 40^{\circ} \mathrm{C}$ or $25^{\circ} \mathrm{C}$ to perform tensile loads at constant displacement rates while the temperature was maintained constant. The imposed temperature cycles are given in Fig. $2 \mathrm{a}$ and $\mathrm{b}$ together with the cooling rates above $150^{\circ} \mathrm{C}$. The corresponding stress-strain curves are shown in symbols in Fig. 2c and $d$. Using these measurements, the five temperature-dependent parameters $\left(\sigma_{0}, H, n, K, m\right)$ are determined by inverse method using a dedicated optimisation software (SiDoLo) developed by Pilvin and Cailletaud (1994).

As shown by Godard (1999) for the solid solution behaviour of AA7010, strain rate sensitivity is negligible at low temperature. In this study, it has been checked that for AA7449 and AA7040, the neSS has a negligible strain rate sensitivity below ca. $300^{\circ} \mathrm{C}$ (not detailed here). Fig. $2 \mathrm{c}$ and d shows that strain hardening is negligible at the SHT temperature. The tensile curves at lower temperature feature strain hardening, which is nevertheless little affected by the cooling paths as assumed in the model. Yield strength increases during cooling due to the combined effect of temperature decrease and precipitation. The strength increase from $100^{\circ} \mathrm{C}$ to $25^{\circ} \mathrm{C}$ is attributed to the formation of hardening clusters at low temperature as observed by in situ small angle X-ray scattering (SAXS) during cooling of AA7449 in the recent paper of Schloth et al. (2014). Clusters were also revealed at temperatures below $250^{\circ} \mathrm{C}$ by in situ SAXS experiments performed on AA7040 at similar cooling rates to the ones encountered during quenching of thick plates (not shown here). Fig. 2 also illustrates the influence of cooling path on yield strength: for instance, yield strengths at $25^{\circ} \mathrm{C}$ and at $100^{\circ} \mathrm{C}$ for AA7449 (Fig. 2c) are higher after a cooling similar to the one of a $75 \mathrm{~mm}$ thick plate in surface than after a cooling similar to the one of a $20 \mathrm{~mm}$ thick plate in surface. For a given cooling path, the flow stress in AA7449 is higher than in AA7040 since it contains more alloying elements available for strengthening by solid solution and precipitation.

\subsection{Determination of onset of accumulation of plastic deformation}

In order to determine $T_{\text {cum }}$, tensile tests at $300^{\circ} \mathrm{C}$ and $325^{\circ} \mathrm{C}$ were followed by a load at $45^{\circ} \mathrm{C}$ as shown in Fig. 3 for AA7449.

When pre-deformation is performed at a temperature lower than $T_{\text {cum }}$, the load curve at low temperature depends on this pre-deformation: the higher the pre-deformation, the higher the stress. This is the case at $300^{\circ} \mathrm{C}$ in Fig. 3a where the load curve at $45^{\circ} \mathrm{C}$ depends on pre-deformation at $300^{\circ} \mathrm{C}$. One-fourth of the ca. $2 \%$ plastic deformation reached at $300^{\circ} \mathrm{C}$ is accumulated at $45^{\circ} \mathrm{C}$ as shown by the stress-strain curve shifted by $0.5 \%$ deformation. Fig. 3 b shows that the influence of pre-deformation at $325^{\circ} \mathrm{C}$ on the load curve at $45^{\circ} \mathrm{C}$ is low.

Similar experiments performed at $350^{\circ} \mathrm{C}$ and $400^{\circ} \mathrm{C}$ for AA7449 and AA7040 showed no accumulation of plastic deformation at these temperatures. From these experiments, the value of $325^{\circ} \mathrm{C}$ has been chosen for $T_{\text {cum }}$ in the models of quenching for both alloys. This means that all the plastic deformation occurring below $325^{\circ} \mathrm{C}$ is accumulated in the model.

This choice leads to a slight overestimation of $p_{\text {cum }}$ since only a part of the plastic deformation at $300^{\circ} \mathrm{C}$ is accumulated at $45^{\circ} \mathrm{C}$ as shown in Fig. 3a.

\subsection{Effect of non-monotonic load on RS}

In order to evaluate the effect of non-monotonic load on RS, tensile tests at $265^{\circ} \mathrm{C}$ were followed by a load at $50^{\circ} \mathrm{C}$ either in tension or in compression as shown in Fig. 4 for AA7040.

This thermo-mechanical testing with the compression step is a simplified attempt to represent what happens at the plate surface during quenching, namely tension at high temperature followed by compression at low temperature. Both specimens experience the same thermal cycle, so that the effect of precipitation on flow stress is the same. In the presence of kinematic hardening, the load curve after tensile pre-straining is higher in tension than in compression. This is the case in Fig. 4b where the yield strength at $50^{\circ} \mathrm{C}$ is ca. $28 \mathrm{MPa}$ higher in tension than in compression. The 

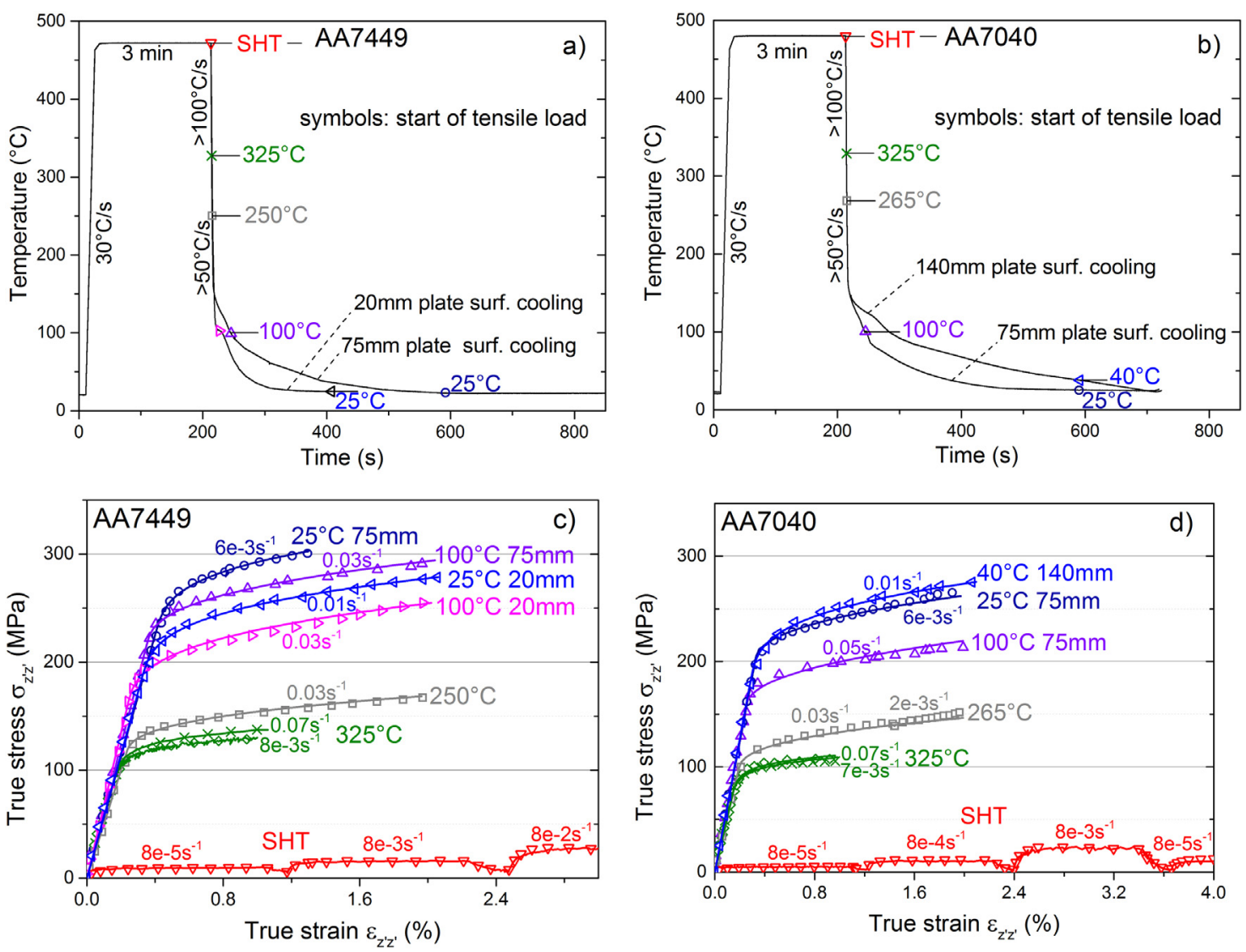

Fig. 2. Surface coolings (top) imposed in Gleeble specimens subjected to tensile loads where (bottom) the measurements (symbols) are fitted using Eq. (3) (solid lines).

difference between flow stress in tension and flow stress in compression decreases with increasing plastic strain at $50{ }^{\circ} \mathrm{C}$. At $0.5 \%$ plastic strain - a value corresponding to the amount of equivalent cumulated plastic strain below $265^{\circ} \mathrm{C}$ at the surface of a $75 \mathrm{~mm}$ plate - the difference is only ca. $10 \mathrm{MPa}$. At $0.9 \%$ plastic strain - a value corresponding to the equivalent cumulated plastic strain below $265^{\circ} \mathrm{C}$ at the surface of a $140 \mathrm{~mm}$ plate there is no difference between flow stress in tension and flow stress in compression. The error of measurement being $\pm 8 \mathrm{MPa}$, the Bauschinger effect can be considered negligible for plates thicker than $70 \mathrm{~mm}$ quenched in cold water. This justifies the assumption of isotropic hardening in Eq. (3). For the $20 \mathrm{~mm}$ plate, the Bauschinger effect can also be neglected because of the lower tensile plastic strain occurring at high temperature compared to that for higher thicknesses.

\subsection{Thermomechanical model of quenching}

The calculated cooling curves at surface and mid-thickness are given in Fig. 5.

The thicker the plate, the larger the temperature difference between mid-thickness and surface, but also the longer the cooling time to reach $20^{\circ} \mathrm{C}$ through the thickness. Surface cooling of $75 \mathrm{~mm}$ and $140 \mathrm{~mm}$ plates is fast from the SHT temperature to ca. $150^{\circ} \mathrm{C}$ but slow below this temperature where precipitation hardening has time to occur. This precipitation hardening leads to higher RS
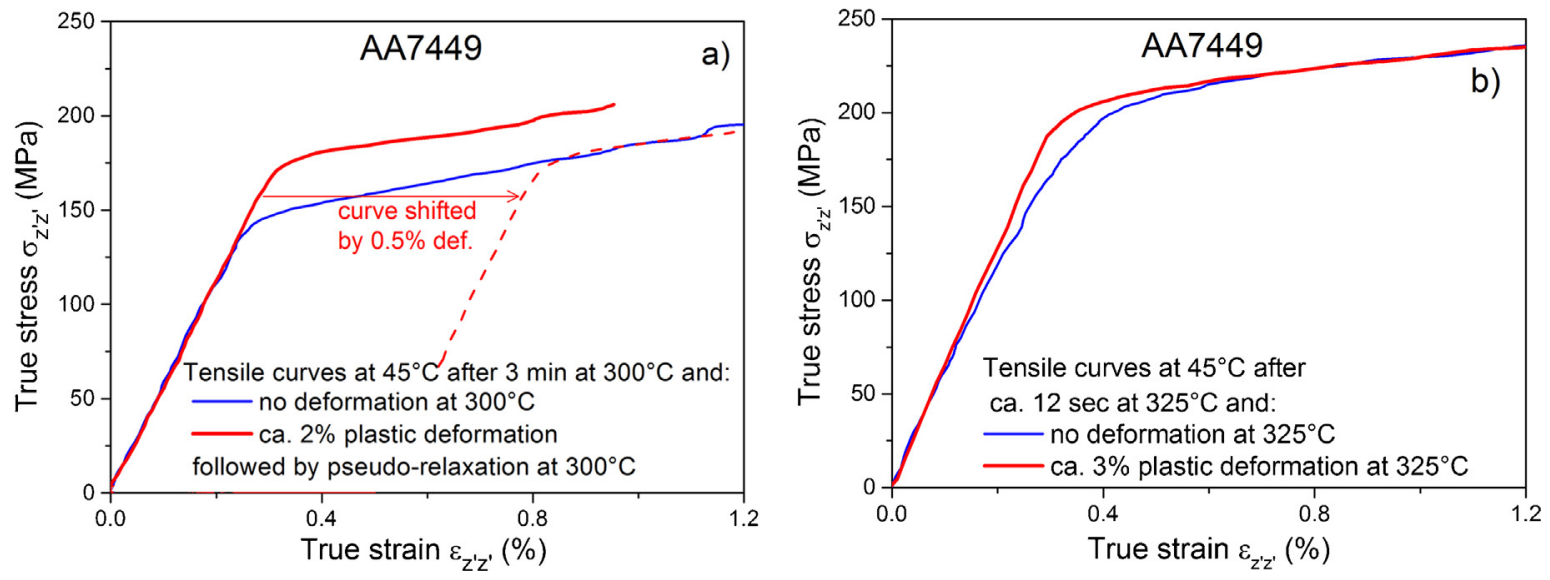

Fig. 3. Measured stress-strain curves of AA7449 specimens subjected to tensile test at $45^{\circ} \mathrm{C}$ with or without pre-deformation at $300{ }^{\circ} \mathrm{C}(\mathrm{a})$ and at $325^{\circ} \mathrm{C}(\mathrm{b})$. 

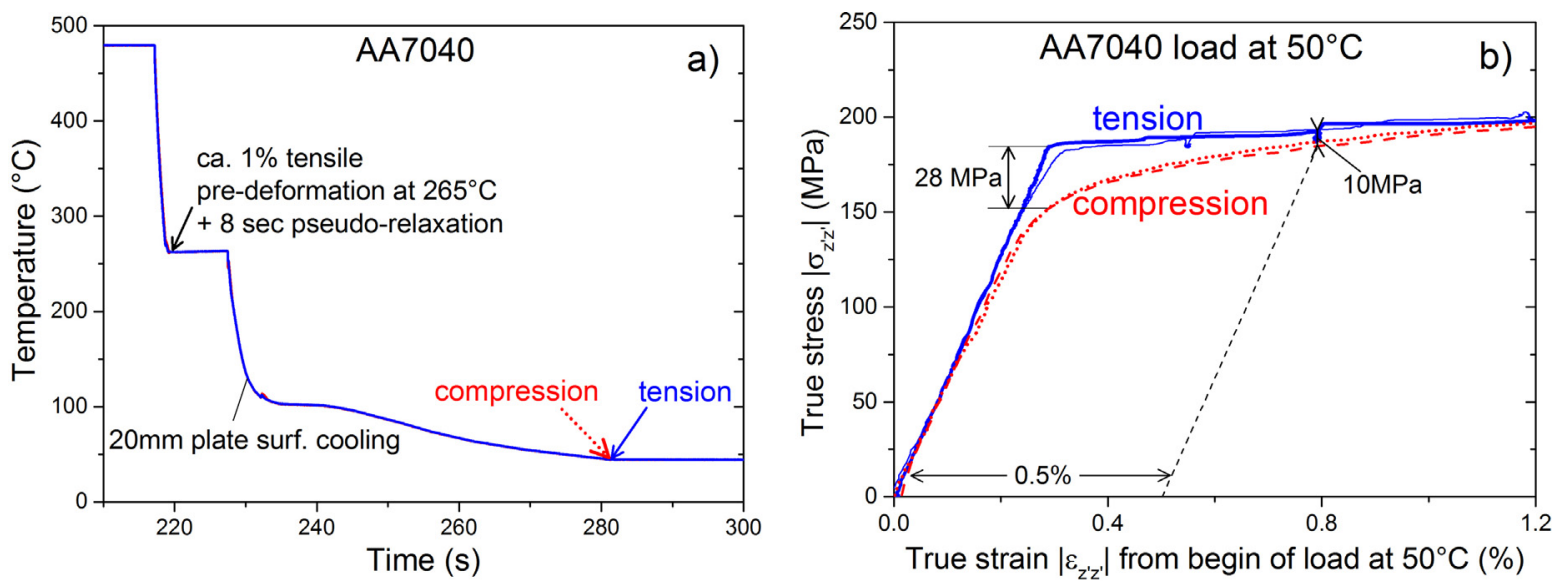

Fig. 4. Cooling imposed in Gleeble specimens (a) subjected to tensile load at $265^{\circ} \mathrm{C}$ followed by tension or compression at $50{ }^{\circ} \mathrm{C}$ (b). Each testing was duplicated.
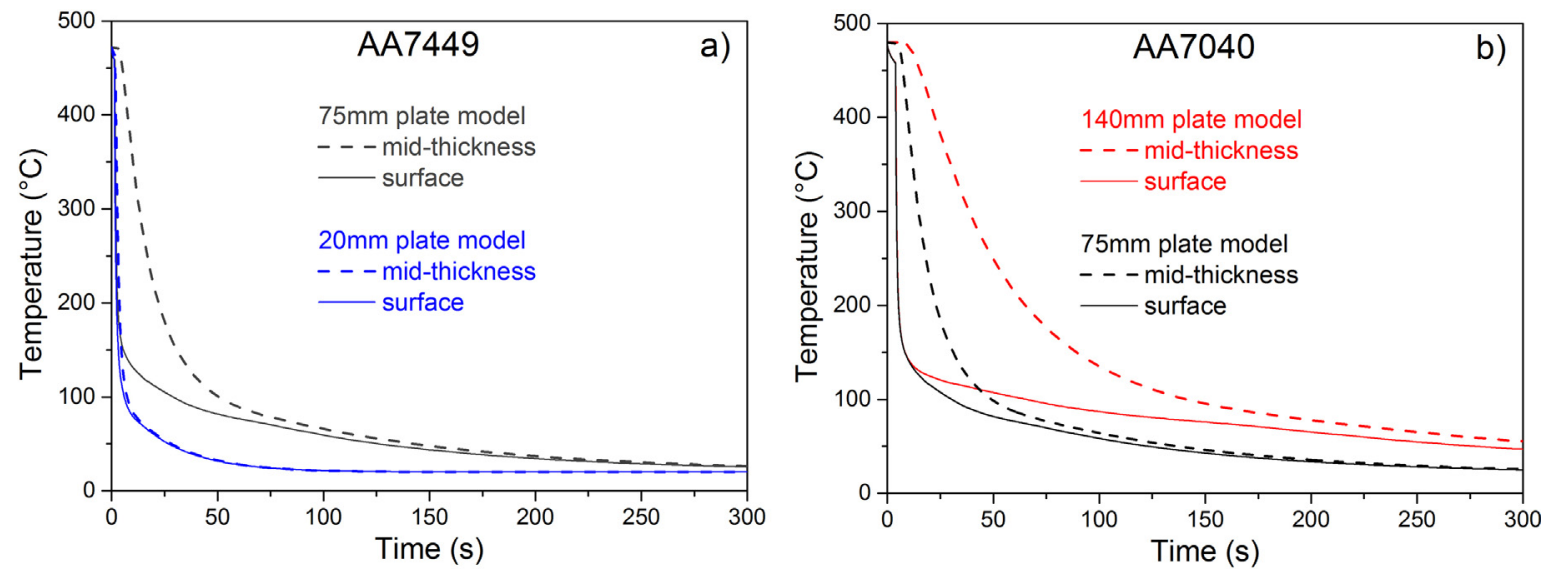

Fig. 5. Calculated cooling curves in AA7449 (a) and AA7040 (b) plates.

as long as there is a significant temperature difference between mid-thickness and surface.

For each of the four cases (different alloys and thicknesses) for the model taking into account precipitation in a simple way, the evolution at the plate surface of the internal stress $\sigma_{x x}$ during quenching is shown in Fig. 6 together with the accumulated equivalent plastic strain $p_{\text {cum }}$ and the in-plane plastic strain component $\varepsilon_{x x}^{p}$.

The plate surface goes from tensile to compressive stresses (Fig. 6a) during quench. Surface plastic strain $\varepsilon_{x x}^{p}$ occurs almost immediately after the begin of quench (Fig. 6c).

For the 75 and the $140 \mathrm{~mm}$ plates, Fig. $6 \mathrm{~b}$ shows that the equivalent accumulated plastic strain begins to increase at $T_{\text {cum }}$ when the surface is still in tension. Then it stops increasing until the surface internal stress reaches again the flow stress (in compression) at about $130^{\circ} \mathrm{C}$. Plastic deformation occurs until the temperature reaches $75^{\circ} \mathrm{C}$. At the end of quenching, below ca. $75^{\circ} \mathrm{C}$, deformation is elastic again due to an increase of the yield stress (Fig. $6 \mathrm{~b}$ and $\mathrm{c}$ ).

For the $20 \mathrm{~mm}$ thick plate, plastic deformation is significantly lower than for higher thicknesses. This is due to a much lower temperature difference between mid-thickness and surface.

At the surface, the final value of $p_{\text {cum }}$ after quenching depends strongly on the plate thickness because the thermal behaviour strongly depends on the plate thickness. For plates between 20 and
$140 \mathrm{~mm}$, the core itself deforms elastically at low temperature (not shown here).

As mentioned previously, the choice of $325^{\circ} \mathrm{C}$ for $T_{\text {cum }}$ could result in a slight overestimation of $p_{\text {cum leading to a stress overes- }}$ timation. To check this point, $T_{\text {cum }}$ was varied from 325 to $250^{\circ} \mathrm{C}$ in the simulations. This resulted in $\sigma_{x x}$ differences lower than $2 \%$ at surface and mid-thickness, meaning that an accurate determination of $T_{\text {cum }}$ is not mandatory. As presented in Section 4.2, a final value of $325^{\circ} \mathrm{C}$ was chosen for the simulations.

The RS profiles obtained using the simple model accounting for precipitation are given in Fig. 7 together with the simulation without precipitation. RS measurements in both alloys in the asquenched state are also shown in Fig. 7.

In all four cases, the simulation without precipitation underestimates the surface RS because the flow stress in the simulation without precipitation is lower than the real flow stress of the surface. The RS at mid-thickness are also underestimated because the compressive stresses are balanced by tensile stresses through the thickness.

The model taking into account precipitation predicts very accurately the RS profile in the $75 \mathrm{~mm}$ thick plates (solid lines in Fig. 7a and $b$ ).

For the $140 \mathrm{~mm}$ thick AA7040 plate (Fig. 7d), the model with precipitation predicts well the RS at surface and satisfactorily at mid-thickness. 


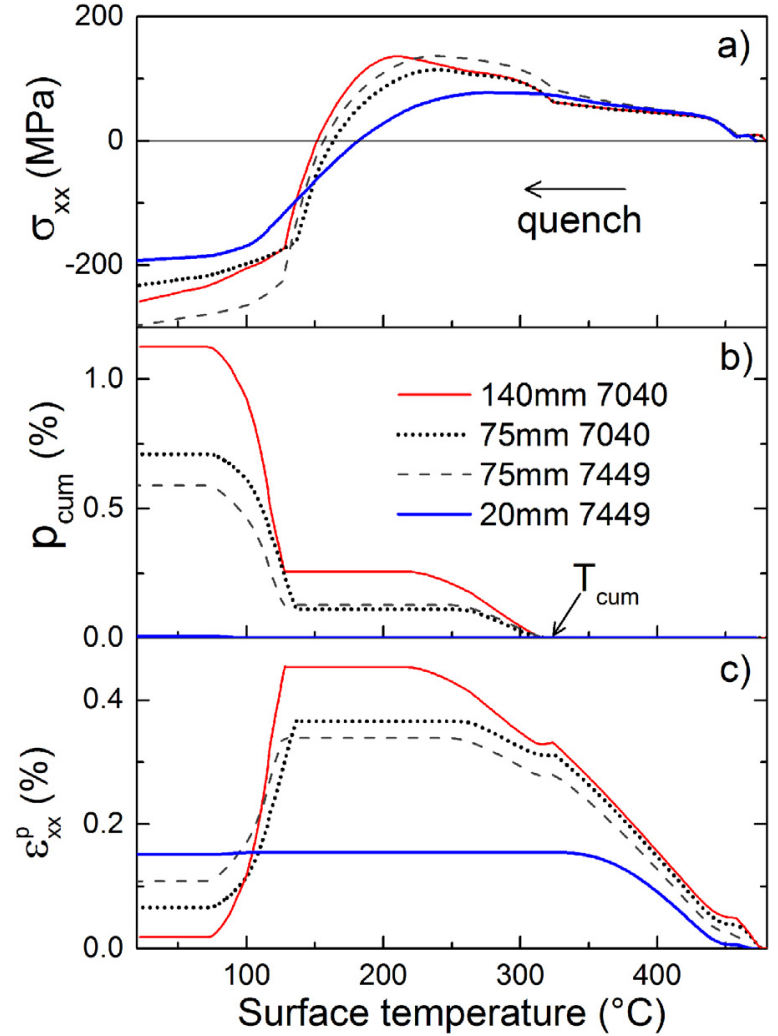

In the $20 \mathrm{~mm}$ thick AA7449 plate (Fig. 7c), the RS at midthickness predicted with or without precipitation compare well with the measurements. Indeed, the cooling of the $20 \mathrm{~mm}$ plate (Fig. 5a) is so fast that precipitation hardening is limited. However, it is not negligible as revealed by the $50 \mathrm{MPa}$ difference between simulations with and without precipitation at the surface. Robinson et al. (2014) measured ca. $180 \mathrm{MPa}$ compressive stress at the surface of a $16 \mathrm{~mm}$ thick AA7010 block. AA7449 containing more alloying elements than AA7010, surface RS in compression should be higher than $180 \mathrm{MPa}$ in a $20 \mathrm{~mm}$ thick AA7449 plate. This is in accordance with the $200 \mathrm{MPa}$ compressive stresses predicted by the simulation with precipitation. Surface measurements by X-ray diffraction would be necessary to verify this value and to check the presence of the shoulder predicted by the model at quarter thickness.

For a given alloy, the greater the plate thickness, the greater the surface RS in as-quenched temper. This is in agreement with the results of Robinson et al. (2014) for cold-water-quenched AA7010 blocks. The RS underestimation of the model without precipitation scales with the thickness. Thus, the thicker the plate is, the more important it is to use a model with precipitation, which predicts the RS profile reasonably well.

The good agreement between the simplified model taking into account precipitation and the measurements shows the relevance of a model based on tensile tests after cooling similar to the one of the surface during quenching. It means however that a few Gleeble tensile tests should be performed for each plate thickness and each alloy one would like to model. These Gleeble tests are:

Fig. 6. Calculated evolution at plate surface using $T_{\text {cum }}=325^{\circ} \mathrm{C}$ of in-plane component of internal stress (a), accumulated equivalent plastic strain (b) and in-plane component of plastic strain (c). The legend is given in (b).

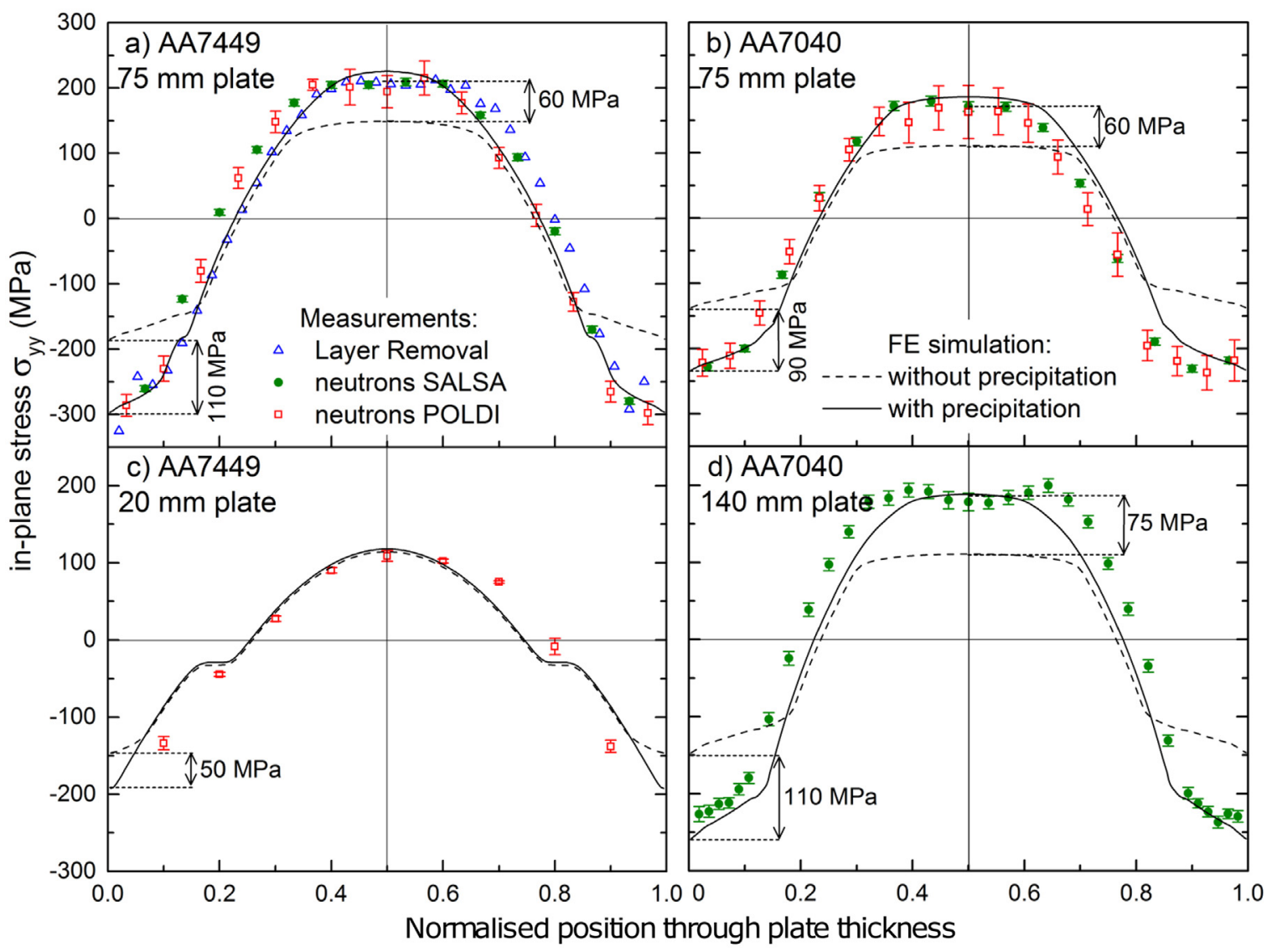

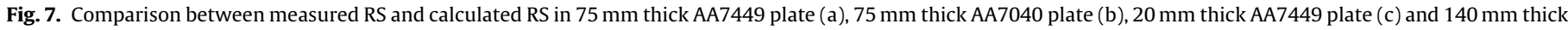
AA7040 plate (d). The legend of the measurements is given in (a) and the legend of the simulations in (b). 
- for each alloy, one tensile test at the SHT temperature and a few tensile tests after rapid cooling between the SHT temperature and $200^{\circ} \mathrm{C}$; and

- for each alloy and plate thickness, two tensile tests at lower temperature (e.g. $25^{\circ} \mathrm{C}$ and $100^{\circ} \mathrm{C}$ ) after a cooling similar to that of the surface during quenching.

This method decreases the number of Gleeble tests compared to the traditional approach based on a yield strength model dependent on precipitation. It is valid as long as the surface yields at low temperature and imposes the stress field on the rest of the plate. For other cases and more complex geometries, a one way coupling temperature-precipitation-stress remains necessary but would require a complete characterisation of precipitation.

\section{Conclusion}

A simple but realistic approach is presented to predict residual stress in thick AA7xxx plates. It accounts for the influence of precipitation hardening on the increase of surface residual stress and requires only a few Gleeble tests. Three plate thicknesses and two different $7 \mathrm{xxx}$ alloys were tested. High temperature tensile tests were achieved for each alloy after fast cooling. The yield strength values were also measured after surface cooling for each plate thickness and each alloy and then introduced in a finite element model to predict RS distribution through the thickness. The main findings are summarised below:

- Precipitation mainly affects yield strength for small strains as assumed in the model.

- Plastic strain recovery has been evidenced above ca. $325^{\circ} \mathrm{C}$ for the two alloys and is taken into account by the present model.

- The Bauschinger effect can be neglected in the case of RS generation during quenching as verified for AA7040.

- The agreement between measured residual stresses and simulated ones with the model accounting for precipitation in a simple way is excellent.

\section{Acknowledgements}

This work is funded by the Competence Centre for Materials Science and Technology (http://www.ccmx.ch/) in the frame of the project entitled "Measurements and modelling of residual stress during quenching of thick heat treatable aluminium components in relation to their microstructure" involving EPF Lausanne, PSI Villigen, Univ. Bretagne-Sud Lorient, Constellium C-TEC and ABB Turbo Systems Ltd. The Gleeble 3500 machine of Université de Bretagne-Sud was co-financed by European Regional Development Fund (ERDF). The authors are indebted to the Institut Laue-Langevin in France and the Swiss Spallation Neutron Source in Switzerland for neutron beam time. The authors are grateful to Prof. P. Pilvin (Univ. Bretagne-Sud) for providing SiDoLo software and J. Costa (Univ. Bretagne-Sud) for the instrumentation of the Gleeble specimens.

\section{References}

Alankar, A., Wells, M.A., 2010. Constitutive behavior of as-cast aluminum alloys AA3104 AA5182 and AA6111 at below solidus temperatures. Mater. Sci. Eng.: A $527,7812-7820$

Boselli, J., Heymes, F., Lassince, P., Lequeu, P., Van Der Veen, S., 2005. Low internal stress Al-Zn-Cu-Mg plates. U.S. Patent Application 11/299,683.
Boyer, J.C., Boivin, M., 1985. Numerical calculations of residual-stress relaxation in quenched plates. Mater. Sci. Technol. 1, 786-792.

Chobaut, N., Repper, J., Pirling, T., Carron, D., Drezet, J.-M., 2012. Residual stress analysis in AA7449 as-quenched thick plates using neutrons and FE modelling. In: Weiland, H., Rollett, A.D., Cassada, W.A. (Eds.), Proceedings of ICAA13. TMS, 285-291.

Chobaut, N., Carron, D., Drezet, J.M., 2014. Monitoring precipitation kinetics in heat treatable aluminium alloys using in-situ resistivity in Gleeble thermomechanical simulator. Mater. Sci. Forum 794-796, 921-925.

Colonna, F., Massoni, E., Denis, S., Chenot, J.L., Wendenbaum, J., Gauthier, E., 1992 On thermoelastic-viscoplastic analysis of cooling processes including phases changes. J. Mater. Processing Technol. 34, 525-532.

Denis, S., Archambault, P., Gautier, E., Simon, A., Beck, G., 2002. Prediction of residual stress and distorsion of ferrous and non-ferrous metals: current status and future developments. J. Mater. Eng. Perform. 11, 92-102.

Deschamps, A., Brechet, Y., 1998. Influence of predeformation and ageing of an $\mathrm{Al}$ $\mathrm{Zn}-\mathrm{Mg}$ alloy-II. Modeling of precipitation kinetics and yield stress. Acta Mater. 47, 293-305.

Drezet, J.-M., Chobaut, N., Schloth, P., Van Swygenhoven, H., 2013. Internal stress generation during quenching of thick heat treatable aluminium alloys. In: Free, M.L., Siegmund, A.H. (Eds.), EPD Congress 2013. TMS, 63-72.

Dubost, B., Bouet-Griffon, M., Jeanmart, P.H., Homette, M.O., 1989. Prediction and minimization of residual stresses in quenched aluminium alloy die forgings. In: Beck, G., Denis, S., Simon, A. (Eds.), Proceedings of the International Conference on Residual Stresses. Springer, pp. 581-586.

Dumont, D., Deschamps, A., Bréchet, Y., Sigli, C., Ehrström, J.C., 2004. Characterisation of precipitation microstructures in aluminium alloys 7040 and 7050 and their relationship to mechanical behaviour. Mater. Sci. Technol. 20, $567-576$.

Fribourg, G., Bréchet, Y., Deschamps, A., Simar, A., 2011. Microstructure-based modelling of isotropic and kinematic strain hardening in a precipitation-hardened aluminium alloy. Acta Mater. 59, 3621-3635.

Godard, D., PhD Thesis INPL, 1999. Influences de la précipitation sur le comportement thermomécanique lors de la trempe d'un alliage $\mathrm{Al}-\mathrm{Zn}-\mathrm{Mg}-\mathrm{Cu}$.

Godard, D., Archambault, P., Houin, J.-P., Gautier, E., Heymes, F., 1998. Mechanical softening kinetics at high temperatures in AlMgZnCu alloy: experimental characterization and microstructural interpretation. In: Sato, T., Kumai, S., Kobayashi, T., Murakami, Y. (Eds.), Proceedings of ICAA6. , pp. 1033-1038.

Godard, D., Archambault, P., Denis, S., Gautier, E., Heymes, F., 1999. Modelling of heat treatment residual stresses. Application to high strength aluminium alloys including precipitation effects. In: Lendvai, J., Réti, T. (Eds.), Proceedings of the 7th International Seminar of IFHT on Heat Treatment and Surface Engineering of Light Alloys. , pp. 249-257.

Godard, D., Archambault, P., Aeby-Gautier, E., Lapasset, G., 2002. Precipitation sequences during quenching of the AA 7010 alloy. Acta Mater. 50, 23192329.

Haaften, W.M., Magnin, B., Kool, W.H., Katgerman, L., 2002. Constitutive behavior of as-cast AA1050, AA3104, and AA5182. Metall. Mater. Trans. A 33, $1971-$ 1980.

Järvstråt, N., Tjøtta, S., 1996. A process model for on-line quenching of aluminium extrusions. Metall. Mater. Trans. B 27, 501-508.

Jeanmart, P., Bouvaist, J., 1985. Finite element calculation and measurement of thermal stresses in quenched plates of high-strength 7075 aluminium alloy. Mater. Sci. Technol. 1, 765-769.

Miller, A.K., 1987. The MATMOD Equations, Unified Constitutive Equations for Creep and Plasticity. Springer, pp. 139-219.

Mo, A., Farup, I., 2000. The effect of work hardening on thermally induced deformations in aluminium DC casting. J. Therm. Stresses 23, 71-89.

Mo, A., Holm, E., 1993. On the use of contitutive internal variable equations for thermal stress predictions in aluminium casting. Model. Ident. Control 14, 43-58.

Myhr, O.R., Grong, Ø., Andersen, S.J., 2001. Modelling of the age hardening behaviour of Al-Mg-Si alloys. Acta Mater. 49, 65-75.

Norris, S., Wilson, I., 1999. Application of 3D numerical modelling for thermal profile optimization on the Gleeble thermomechanical simulator. Model. Simul. Mater. Sci. Eng. 7, 297-309.

Pilvin, P., Cailletaud, G., 1994. Identification and inverse problems related to material behaviour. In: Bui, H.D., Tanaka, M., Bonnet, M., Maigre, H., Luzzato, E., Reynier, M. (Eds.), Proceedings of the Second International Symposium on Inverse Problems, Balkema. , pp. 79-86.

Reich, M., Kessler, O., 2011. A study of the Bauschinger effect in undercooled aluminium alloys. In: Proceedings of the 3rd International Conference on Distortion Engineering, pp. 203-210.

Robinson, J.S., Tanner, D.A., Truman, C.E., 2014. 50th Anniversary Article: The origin and management of residual stress in heat-treatable aluminium alloys. Strain 50, 185-207

Schloth, P., Wagner, J.N., Fife, J.L., Menzel, A., Drezet, J.-M., Van Swygenhoven, H., 2014. Early precipitation during cooling of an Al-Zn-Mg-Cu alloy revealed by in situ small angle X-ray scattering. Appl. Phys. Lett. 105, 101908.

Yu, X., Robinson, J.S., 2007. Measurement of the Heat Transfer Coefficient During Quenching of the Aluminium Alloy 7449, COMPACT Project Report. 